\title{
Detection of germline mutations in the von Hippel-Lindau disease gene by the primer specified restriction map modification method
}

\author{
T Kishida, F Chen, M I Lerman, B Zbar
}

\begin{abstract}
Von Hippel-Lindau disease (VHL) is an inherited disorder characterised by a predisposition to develop tumours in the eyes, central nervous system, kidneys, and adrenal glands. Recently the VHL gene was cloned and shown to be mutated in $75 \%$ of US and Canadian VHL families. To develop simple, rapid methods for the detection of mutations found in large numbers of affected people, we designed tests based on the primer specified restriction site modification method. These tests have proved useful in identifying asymptomatic mutated VHL gene carriers who have the nt $505 \mathrm{~T}$ to $\mathrm{C}$ mutation or the nt $686 \mathrm{~T}$ to $\mathrm{C}$ mutation. Together with an MspI digestion test which can detect a mutation hot spot in codon 238, polymerase chain reaction/restriction endonuclease based tests can now detect VHL mutations in more than $\mathbf{5 0 \%}$ of VHL type 2 families.
\end{abstract}

(f Med Genet 1995;32:938-941)

Von Hippel-Lindau disease (VHL) is an autosomal dominantly inherited neoplastic disorder characterised by a predisposition to develop retinal angiomas, cerebellar haemangioblastomas, phaeochromocytomas, renal cell carcinomas, pancreatic cysts, and epididymal cysts. Clinical screening for early detection of eye, brain, and kidney tumours has been recommended. ${ }^{12}$ The detailed genetic mapping of the VHL disease gene to chromosome 3p25$26^{3-8}$ enabled presymptomatic diagnosis of VHL disease by linkage analysis in some families. ${ }^{910}$ Recently, the VHL tumour suppressor gene was isolated by positional cloning methods. ${ }^{11}$ It is now feasible to identify specific mutations in affected subjects and to follow these mutations in families. So far, germline mutations of the VHL gene have been described in families from the USA, ${ }^{1213}$ England, ${ }^{14}$ Germany, ${ }^{15}$ and Japan (T Shuin, personal communication). The spectrum of mutations in the VHL gene among these different families is diverse including 80 different point mutations, small deletions/insertions, and large deletions $(4-380 \mathrm{~kb}) .^{12-15}$ Thus, identification of an unknown mutation requires several specialised, time consuming methods such as Southern blotting, pulsed field gel electrophoresis, or single strand con- formational polymorphism analysis (SSCP) and DNA sequencing.

Previously we detected 85 different mutations in 114 VHL families and could identify genotype-phenotype relationship in these families. ${ }^{12}$ The types of mutations responsible for VHL without phaeochromocytoma (VHL type 1) differed from those responsible for VHL with phaeochromocytoma (VHL type 2). Fiftysix percent of the mutations responsible for VHL type 1 were microdeletions/insertions, nonsense mutations, or large deletions $(4-380 \mathrm{~kb}) ; 96 \%$ of the mutations responsible for VHL type 2 were missense mutations. ${ }^{12}$

The VHL families with point mutations that generated or destroyed unique restriction sites could be further tested for asymptomatic gene carriers by restriction enzyme digestion of polymerase chain reaction (PCR) products. However, point mutations in several families did not result in changes of restriction sites. $\mathrm{Nt}$ $505 \mathrm{~T}$ to $\mathrm{C}$ and $\mathrm{nt} 686 \mathrm{~T}$ to $\mathrm{C}$ were among the mutations which did not change a restriction site. $\mathrm{Nt} 505 \mathrm{~T}$ to $\mathrm{C}$ was found in $14 \mathrm{VHL}$ families in the Black Forest area of Germany $^{15}$ and two families in the USA. ${ }^{12}$ Mutation at $\mathrm{nt} 686 \mathrm{~T}$ to $\mathrm{C}$ was found in two large families in the USA. ${ }^{12}$ There were more than 100 patients with the 505 mutation and more than 75 patients with the 686 mutation. Many asymptomatic relatives in these families require genetic testing to determine whether they carried the mutant VHL gene. Haliassos et $a l^{16}$ introduced the primer specified restriction map modification method for analysis of a point mutation in the Kirsten ras oncogene that did not require restriction site changes. Point mutations in cystic fibrosis, retinitis pigmentosa, cholesteryl ester transfer protein deficiency, multiple endocrine neoplasia (MEN) type 2A, and familial medullary thyroid carcinoma have been analysed with this method. ${ }^{17-20}$ In this report we used this method to detect the nt 505 or the nt 686 change in the VHL gene and could confirm its usefulness in testing a large number of VHL patients.

\section{Methods \\ FAMILIES}

We tested two large VHL families with point mutations at nt $505 \mathrm{~T}$ to $\mathrm{C}$ (family 3127 ) or nt $686 \mathrm{~T}$ to $\mathrm{C}$ (family 4475). Both mutations were found by SSCP and DNA sequencing previously. ${ }^{12}$ No restriction site changes were available to detect these mutations. Forty-seven members were affected in family 3127 and we 
have 10 DNA samples including six clinically diagnosed VHL patients. Family 4475 had 51 affected members and we tested four affected patients who are fairly distant from each other in the pedigree. ${ }^{22}$ In our previous screening of 114 VHL families we found another family with the same change at nt 505 (family 3476) and another family with the same change at nt 686 (family 4408).

PCR WITH MODIFIED PRIMERS AND RESTRICTION ENZYME DIGESTION

To create the available restriction site change in the mutation region, we designed modified primers for the PCR reaction. For the nt 505 $\mathrm{T}$ to $\mathrm{C}$ mutation the primer TK 1 (5'TGCCAGGCGGCAGCGTTGGAT- $3^{\prime}$ ) and the primer MA2A (5'-GGCCCGTGCTGCGCTCGGTGAACT-3') amplify 135 bp PCR product. The primer TK 1 has a mismatch (underlined) with the genomic sequence and creates an FokI site in the mutant allele of the PCR product. For the nt $686 \mathrm{~T}$ to $\mathrm{C}$ substitution the primer TK 3 (5'-TCCGGACAACCTGGAGGCATCGCTCTTGC-3') and the primer YH1A (5'-TTCCTTGTACTGAGACCCTAGT-3') amplified 98 bp fragments. The primer TK 3 contains a mismatch (underlined) which provides an AciI site only in a mutant allele. PCR was performed with an initial three minutes' denaturation at $95^{\circ} \mathrm{C}$ followed by 30 cycles of 45 seconds at each of $95^{\circ} \mathrm{C}, 59^{\circ} \mathrm{C}, 72^{\circ} \mathrm{C}$, and final extension for five minutes at $72^{\circ} \mathrm{C}$ in a PCR 9600 Perkin Elmer Cetus machine. PCR products were ethanol precipitated then dissolved in $10 \mu \mathrm{l}$ of TE; 10 units of FokI or AciI (New England Biolabs) and $1 \cdot 1 \mu \mathrm{l}$ of $10 \times$ buffer supplied by the manufacturer were added and incubated at $37^{\circ} \mathrm{C}$ for three hours. The digested products were electrophoresed in a $2 \% \mathrm{TBE}$ agarose gel and visualised by ethidium bromide staining.

\section{Results}

In the previous study we detected two point mutations in the VHL gene that did not create or destroy a restriction site. As these mutations were found in large families that contained many at risk asymptomatic relatives, we created simple methods to test these mutations. One mutation was a $T$ to $C$ substitution at nt 505 found in families 3127 and 3476; the other was a $T$ to $C$ substitution at nt 686 found in families 4475 and 4408 . DNA samples from families 3127 and 3476 were amplified by PCR with primers TK1 and MA2A, then the 135 base pair PCR product was digested by FokI. Affected patients in both families showed a $104 \mathrm{bp}$ fragment originating from the nt $505 \mathrm{~T}$ to $\mathrm{C}$ mutation (figure $A, B$ ). One unaffected member in family 3476 (patient II-3) and three asymptomatic young sibs in family 3127 (II.5, 7, 8) showed the $104 \mathrm{bp}$ fragment. Patient II. 3 in family 3476 was considered to be an obligate gene carrier because of the family history. The three asymptomatic children who carry the mutant gene need clinical screening. For detection of the mutation at $\mathrm{nt} 686 \mathrm{~T}$ to $\mathrm{C}$ substitution, we tested affected patients from family 4475 and 4408. DNA samples from these families were PCR amplified with primers TK3 and YH1A and then digested by AciI. Only the mutant allele created $68 \mathrm{bp}$ fragment in addition to $98 \mathrm{bp} P C R$ product in all affected subjects (figure $\mathrm{C}$ ).

\section{Discussion}

Many genetic diseases can be diagnosed by identification of mutations in the gene responsible. Cystic fibrosis, neurofibromatosis, muscular dystrophy, and MEN type $2 \mathrm{~A}$ are examples of hereditary diseases that can be subjected to DNA diagnosis. When the changes in the gene are a single base substitution or small deletion/insertion that create or destroy a unique restriction site, the presence of a mutation can be detected by digestion of the PCR product with a specific restriction enzyme. We tested 20 VHL families with this conventional restriction enzyme test and reconfirmed the identified mutation (data not shown). In cases of mutations that do not change any restriction site, primer specified restriction site modification makes it possible to detect changes easily with restriction enzymes. We used this method to detect two point mutations found in two large VHL kindreds and could confirm the mutation in affected patients as well as asymptomatic mutant gene carriers. The other members of these families are being screened with this method at other clinical laboratories.

In MEN type $2 \mathrm{~A}, 84 \%$ of the causative mutation in the RET gene was in codon $634 .^{21}$ In this case it was possible to screen the unknown genetic change in new MEN type 2A families by PCR amplification of the region followed by digestion with the appropriate restriction enzyme. ${ }^{1920}$ In VHL, although the types of mutation vary from large deletions $(4-380 \mathrm{~kb})$ to many different point mutations, in some situations tests with restriction enzymes are still useful for detecting unknown mutations in new families. VHL families can be classified into two types based on the clinical heterogeneity and presence or absence of phaeochromocytoma. ${ }^{22-24}$ VHL type 2 was defined by the presence of phaeochromocytoma and $96 \%$ of the mutations responsible for the VHL type 2 were missense mutations including frequent mutations at codon $238 .^{12}$ This mutational hot spot at codon 238 (C to $\mathrm{T}$ substitution at nt 712 and $G$ to $A$ at nt 713) has been reported from several investigators from the USA, ${ }^{12}$ England, ${ }^{14}$ and Japan (T Shuin, personal communication), and was strongly correlated with VHL type 2 . In our previous study $10 / 23(43 \%)$ of VHL type 2 families had this hot spot mutation. ${ }^{12}$ These two mutations found in codon 238 were detected easily by a restriction enzyme test because they destroyed an MspI site. Those two families with nt 505 mutation and one of the families with nt 686 mutation were also classified as VHL type 2. Therefore, in 13 out of 23 VHL type 2 families $(57 \%)$ we were able to detect their mutations by PCR-restriction enzyme based 

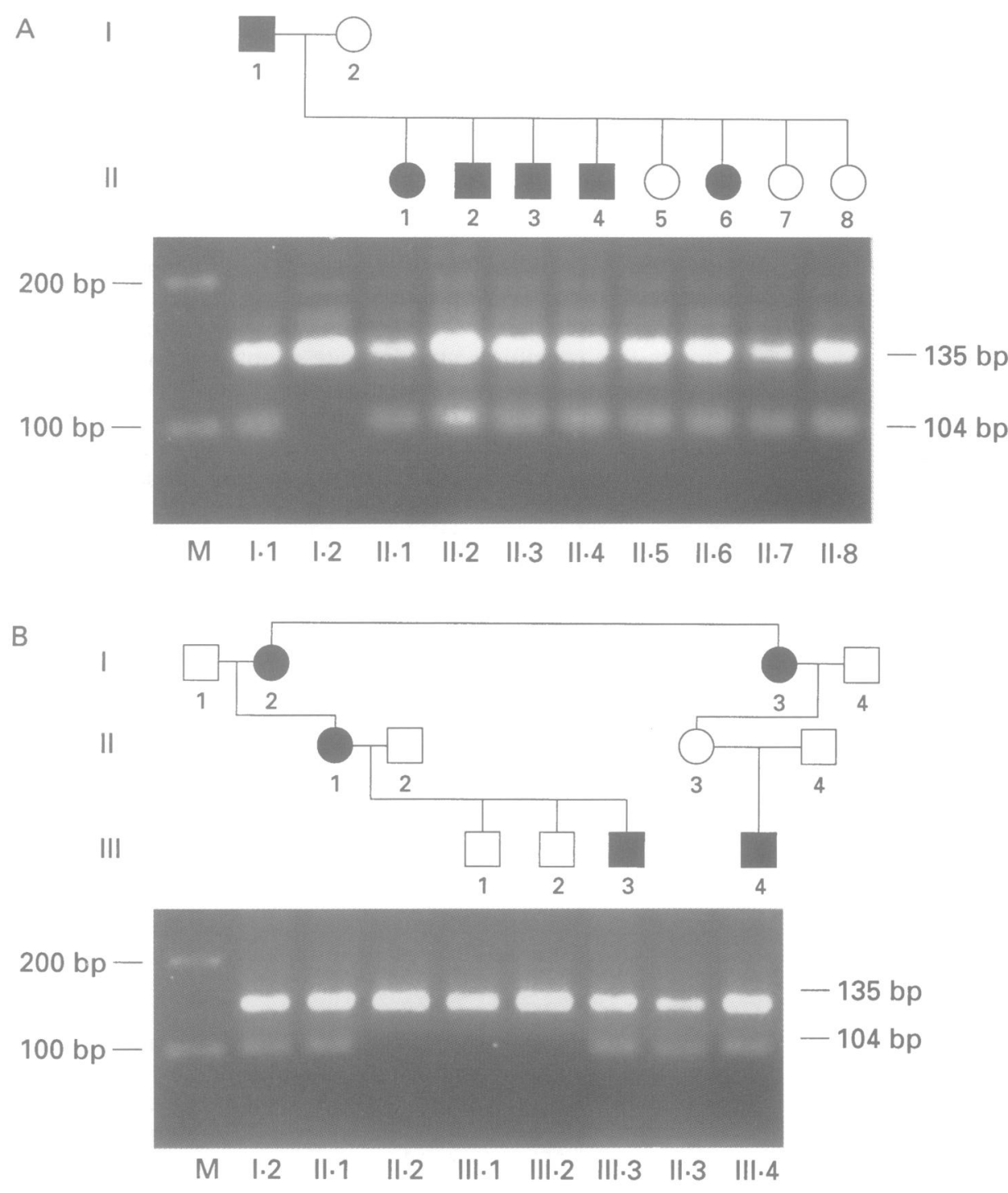

C

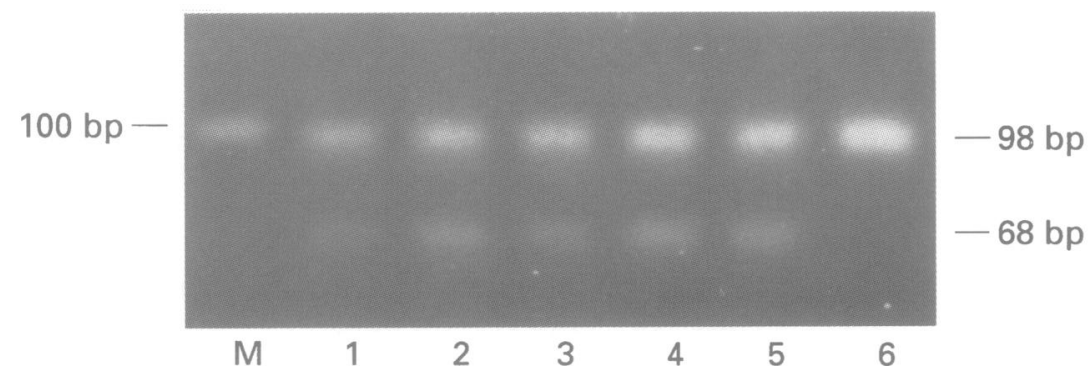

Detection of germline mutations by primer specified restriction map modification. $(A, B)$. Detection of nt $505 T$ to $C$ mutation. DNA from members of family $3476(A)$ and $3127(B)$ were PCR amplified with primers TK1 and MA2A and then digested by FokI as described in Methods. Only a mutant allele produced 104 and 31 bp fragments (the smaller fragment is not shown in this figure) in addition to $135 \mathrm{bp} P C R$ product. Closed symbols: clinically diagnosed VHL patients. Open symbols: clinically asymptomatic subjects. M: DNA size marker. (C) Detection of nt $686 \mathrm{~T}$ to $C$ mutation. Four DNA samples from affected members in a VHL family 4475 (lanes 1-4), one from family 4408 (lane 5), and a normal control (lane 6) were amplified by PCR with primer TK3 and YH1A by AciI digestion. Mutant 5), and a normal control (lane 6) were amplified by PCR with primer TK3 and YHIA by Acil digestion. Mutant
alleles created 68 and 30 bp fragments (only the larger fragment was shown) in addition to 98 bp PCR product. M: DNA size marker.

tests. On the other hand, the mutations found in the VHL type 1 families consisted of many types of large deletions, small deletions/insertions, or point mutations. No hot spots were found in the mutations of the VHL type 1 families, ${ }^{12}$ so it is not practical to apply restriction enzyme based tests for screening of unknown mutations in the VHL type 1 patients. 
Detection of mutations in VHL type 2 families by restriction enzyme

\begin{tabular}{lllll}
\hline Mutation & Restriction site change & \multicolumn{3}{l}{ No of VHL type 2 families } \\
\cline { 3 - 5 } & & USA ${ }^{12}$ & England $^{14}$ & Germany $^{15 *}$ \\
\hline nt 712 C to T & MspI & 4 & 3 & 0 \\
nt 713 G to A & MspI & 6 & 4 & 0 \\
nt 505 T to C & FokI & 2 & 0 & 14 \\
nt 686 T to C & AciI & 1 & 0 & 0 \\
Total & & $13 / 23 \ddagger$ & $7 / 11$ & $14 / 14$ \\
\hline
\end{tabular}

* VHL families in the Black Forest area.

t Available by PCR with primer specified modification

$\ddagger$ Number of VHL type 2 families with nt $712,713,505$, or 686 mutation/number of total VHL type 2 families.
6 Seizinger BR, Smith DI, Filling-Katz MR, et al. Genetic flanking markers refine diagnostic criteria and provide flanking markers refine diagnostic criteria and provide insights into the genetics of von Hippel-L
Proc Natl Acad Sci USA 1991;88:2864-8.

7 Richards FM, Maher ER, Jones MH, et al. Detailed genetic mapping of the von Hippel-Lindau disease tumor suppressor gene. F Med Genet 1993;30:104-7.

8 Crossey PA, Maher ER, Jones MH, et al. Genetic linkage between von Hippel-Lindau disease and three microsatellite polymorphisms refines the localization of the VHL locus. Hum Mol Genet 1993;2:279-82.

9 Maher ER, Bentley E, Payne SJ, et al. Presymptomatic diagnosis of von Hippel-Lindau disease with flanking DNA markers. F Med Genet 1992;29:902-5.

10 Glenn GM, Linehan WM, Hosoe S, et al. Screening for von Hippel-Lindau disease by DNA polymorphism analysis. $\dddot{7 A M A}$ 1992;267:1226-31.

11 Latif F, Tory K, Gnarra J, et al. Identification of the von Hippel-Lindau disease tumor suppressor gene. Science 1993;260:1317-20.

Even with time consuming, expensive, and radioactive methods such a Southern blotting, pulsed field electrophoresis, and SSCP and DNA sequencing, mutations in the VHL gene could be detected in $70 \%$ of VHL type 1 families and $88 \%$ of VHL type 2 families. ${ }^{12}$ Although much effort is still needed to detect mutations in the VHL type 1 patients, screening of mutations in the VHL type 2 patients can be simplified with restriction enzyme based tests. Our method proved to be useful not only in the USA but also in England and Germany (table).

In summary, we described a convenient method of detecting point mutations at nt 505 $T$ to $C$ and nt $686 \mathrm{~T}$ to $\mathrm{C}$ in the VHL gene and its possible role for the screening of subjects in VHL type 2 families.

1 Karsdorp N, Elderson A, Wittebol-Post D, et al. Von HippelLindau disease: new strategies in early detection and treatment. $A m \mathcal{F}$ Med 1994;97:158-68.

2 Moore AT, Maher ER, Rosen P, et al. Ophthalmological screening for von Hippel-Lindau disease. Eye 1991;5: 723-8.

3 Seizinger BR, Rouleau GA, Ozelius LJ, et al. Von HippelLindau disease maps to the region of chromosome 3 associated with renal cell carcinoma. Nature 1988;322: 268-9.

4 Hosoe $\dot{S}$, Brauch H, Latif F, et al. Localization of the von Hippel-Lindau disease gene to a small region of chromosome 3. Genomics 1990;8:634-40.

5 Maher ER, Bentley E, Yates JRW, et al. Mapping of the von Hippel-Lindau disease locus to a small region of chromosome $3 \mathrm{p}$ by genetic linkage analysis. Genomics 1991;10:957-60.

Chen F, Kishida T, Yao M, et al. Germline mutations in the von Hippel-Lindau disease tumor suppressor gene:

13 Whaley JM, Naglich J, Galbert L, et al. Germ-line mutations in the von Hippel-Lindau tumor suppressor gene are similar to somatic von Hippel-Lindau aberrations in sporadic renal cell carcinoma. Am f Hum Genet 1994;55: 1092-102.

14 Crossey POA, Richards FM, Foster K, et al. Identification of intragenic mutations in the von Hippel-Lindau tumor suppressor gene and correlation with disease phenotype. Hum Mol Genet 1994;3:1303-8.

15 Brauch H, Kishida T, Glavac D, et al. Nucleotide 505 germline mutation in the VHL tumor suppressor gene correlates with pheochromocytoma in von Hippel-Lindau disease. Hum Genet 1995;95:551-6.

16 Haliassos A, Chomel JC, Tesson L, et al. Modification of enzymatically amplified DNA for the detection of point mutations. Nucleic Acids Res 1989;17:3606.

17 Sorscher EJ, Huang Z. Diagnosis of genetic disease by primer-specified restriction map modification, with application to cystic fibrosis and retinitis pigmentosa. Lance 1991;337:1115-8.

18 Inazu A, Koizumi J, Haraki T, et al. Rapid detection and prevalence of cholesteryl ester transfer protein deficiency caused by an intron 14 splicing defect in hyperalphalipoproteinemia. Hum Genet 1993;91:13-16.

19 Xu F, Yu H, Maurer LH, et al. Germline RET mutations in MEN $2 \mathrm{~A}$ and FMTC and their detection by simple DNA diagnostic tests. Hum Mol Genet 1994;3:635-8.

20 McMahon R, Mulligan LM, Healey CS, et al. Direct, nonradioactive detection of mutations in multiple endocrine neoplasia type 2A families. Hum Mol Genet 1994;3:643-6.

21 Mulligan LM, Eng C, Healey CS, et al. Specific mutations of the RET proto-oncogene are related to disease phenoof the RET proto-oncogene are related to disease pheno-

22 Lamiell JM, Salazar FG, Hsia YE. von Hippel-Lindau disease affecting 43 members of a single kindred. Medicine (Baltimore) 1989;6:1-29.

23 Glenn GM, Daniel LN, Choyke P, et al. Von Hippel-Lindau disease: distinct phenotypes suggest more than one mutant allele at the VHL locus. Hum Genet 1991;87:207-10.

24 Neumann HPH, Weistler OD. Clustering of features of von Hippel-Lindau disease: evidence of a complex genetic locus. Lancet 1991;337:1052-4. 